CLINICAL STUDY

\title{
Adiponectin: serum levels, promoter polymorphism, and associations with birth size and cardiometabolic outcome in young adults born large for gestational age
}

Ana Carolina Bueno ${ }^{1}$, Aniette R Espiñeira ${ }^{1}$, Fábio L Fernandes-Rosa ${ }^{1}$, Roberto Molina de Souza ${ }^{1}$, Margaret de Castro $^{2}$, Ayrton Custódio Moreira ${ }^{2}$, Heloísa Bettiol ${ }^{1}$, Marco Antonio Barbieri ${ }^{1}$ and Sonir R Antonini ${ }^{1}$

Departments of ${ }^{1}$ Pediatrics and ${ }^{2}$ Internal Medicine, School of Medicine of Ribeirao Preto, University of Sao Paulo, Avenida Bandeirantes 3900 , Monte Alegre, CEP 14049-900 Ribeirao Preto, Sao Paulo, Brazil

(Correspondence should be addressed to S R Antonini; Email: antonini@fmrp.usp.br)

\begin{abstract}
Objective: To assess whether the $-11391 \mathrm{G}>\mathrm{A}$ polymorphism in the regulatory region of the adiponectin gene $(A D I P O Q)$ is associated with birth size, postnatal growth, adiponectinemia, and cardiometabolic risk in adult life.

Design: Case-control study nested within a prospective cohort of 2063 community subjects born in 1978/1979 and followed since birth to date.

Methods: ADIPOQ - 11391G > A genotype-phenotype associations were evaluated in 116 subjects born large for gestational age (LGA) and 392 gender-matched controls at birth (birth size), at 8-10 years (catch-down growth), and at 23-25 years of age (cardiometabolic profile).

Results: The -11391 A variant allele frequency was higher in LGA subjects $(P=0.04)$. AA genotype was associated with augmented probability of being born LGA (odds ratio $=4.14 ; 95 \%$ confidence interval: $1.16-16.7 ; P=0.03)$. This polymorphism was associated neither with body composition nor with postnatal growth pattern. At the age of 23-25 years, the $-11391 \mathrm{~A}$ variant allele was associated with higher serum adiponectin levels (GG: $10.7 \pm 6.2$ versus GA: $12.2 \pm 6.5$ versus AA: 14.2 $\pm 6.8 \mu \mathrm{g} / \mathrm{ml} ; P<0.01)$. Subjects born LGA presented higher body mass index (BMI; $P=0.01$ ), abdominal circumference $(P=0.04)$, blood pressure $(P=0.04)$, and homeostasis assessment model for insulin resistance $(P=0.01)$ than adequate for gestational age. Symmetry at birth did not influence these variables. The occurrence of catch-down of weight was associated with lower BMI and abdominal circumference $(P<0.001)$ at $23-25$ years.

Conclusions: The $-11391 \mathrm{~A}$ ADIPOQ gene variant was associated with increased chance of being born LGA and with higher adiponectin levels in early adult life.
\end{abstract}

European Journal of Endocrinology 162 53-60

\section{Introduction}

Children born large for gestational age (LGA) seem to present increased risk to develop type 2 diabetes (T2D) and cardiovascular disease when compared with those born adequate for gestational age (AGA) $(1,2)$. The etiology of prenatal overgrowth is heterogeneous. Gestational diabetes, large maternal size, obesity, and excessive maternal weight gain during pregnancy are important risk factors (3). In cases of LGA associated with gestational diabetes, fetal hyperglycemia leads to hyperinsulinism, increased fat and lean mass, and glycogen storages (4). Additionally, in some LGA subjects, hyperinsulinemia can occur independent of gestational diabetes (5). These babies develop asymmetric fetal overgrowth and present high frequency of childhood obesity, impaired glucose tolerance, and T2D in adolescence or later (6). In LGA subjects born to nondiabetic or nonobese mothers, there may be direct genetic influences on fetal growth (7), which may also be important in the adult susceptibility to diseases.

Adiponectin is an adipokine that presents insulinsensitizing, anti-inflammatory, and antiatherosclerotic properties (8). In children and in adolescents, low adiponectinemia is closely related to adiposity (9). Plasma adiponectin is also reduced in adults with insulin resistance (IR), obesity, T2D, and coronary artery disease (10), suggesting a negative feedback of the adipose tissue in its production (8). Hypoadiponectinemia is also associated with other components of metabolic syndrome, such as hypertension and dyslipidemia (11).

Adiponectin regulates insulin action, which is a key component of the fetal development (12). A very recent study suggested a role for adiponectin in prenatal growth (13). Adiponectin levels in cord blood are 
significantly higher than adult concentrations, and are positively correlated with gestational age (14) and birth weight (15). Plasma adiponectin decreases physiologically between the first and second years of life (16).

Single-nucleotide polymorphisms (SNPs) in the adiponectin gene $(A D I P O Q)$ have been associated with adiponectin levels $(17,18)$, changes in insulin sensitivity, and with the risk for T2D and coronary artery disease (18-20). More specifically, association studies revealed a link between the SNP $-11391 \mathrm{G}>\mathrm{A}$, located at the $A D I P O Q$ promoter region, and adiponectin levels, IR, and T2D (20, 21).

To our knowledge, no previous studies have investigated the association between $A D I P O Q$ polymorphisms with birth size and adiponectin outcome later in life. In the present study, we compared body symmetry at birth, pattern of postnatal growth, serum adiponectin levels, and cardiometabolic parameters in early adult life in a large cohort of subjects born LGA with those of a control population born AGA. Furthermore, we evaluated whether variability in birth size and associated outcomes are related to the ADIPOQ - 11391G>A polymorphism.

\section{Methods}

\section{Subjects}

This was a case-control study nested within a longitudinal cohort and followed since birth to date in our Institution. Briefly, this cohort study included four follow-ups (birth, 8-10, 18, and 23-25 years) starting with 6748 singletons corresponding to $91 \%$ of the total liveborns between June 1st, 1978 and May 30th, 1979 in the city of Ribeirao Preto, south-east of Brazil. In the last follow-up, at the age of 23-25 years, 2063 subjects were enrolled. Anthropometric, clinical, and biochemical information were accounted in a database (22).

For the present case-control study, subjects were selected and divided into two groups according to the birth size (23). Subjects presenting birth weight above the 90th percentile or two standard deviations above the mean for gestational age and sex were classified as LGA. Subjects with birth weight between the 10 and the 90th percentile or between two standard deviations above or below the mean for gestational age and sex were classified as AGA. Among subjects evaluated at 23-25 years of age, we studied 116 LGA (93\% of total LGA). Control group was comprised of 392 sex-matched subjects born AGA (23\% of total AGA). The occurrence of catch-down of weight was analyzed in a subset of 62 LGA subjects who had also been evaluated at the age of 8-10 years.

Exclusion criteria were endocrine disorders, chronic diseases, and skeletal abnormalities. Subjects who were one of a twin or referred history of drug intake that cause interference in the somatotropic axis were not included.

At birth and childhood, written consent was obtained from the subject's parent. At young adult life, all subjects gave written informed consent. The study was approved by the University Hospital Ethical Committee (protocol no. 3444/2008).

\section{Phenotype measurements}

At birth, anthropometric measurements included length and weight were measured. Symmetry was evaluated by Rohrer's ponderal index (PI= birth weight $(\mathrm{g}) /$ birth length $\left.{ }^{3}(\mathrm{~cm}) \times 100\right)$, where subjects with $\mathrm{PI}<2.25$ were considered asymmetric (light for length), $2.25<\mathrm{PI}<3.1$ symmetric and $\mathrm{PI}>3.1$ asymmetric (heavy for length). These subjects were born in $1978 / 1979$ and, at the time, the presence of gestational diabetes was not universally assessed. To overcome the lack of this information in our cohort, we assumed that a subset of LGA subjects born asymmetric (PI>3.1) were likely to be an offspring of diabetic mothers (24).

Variation in SDS for weight and length between birth and 8-10 years of age was calculated. Decrease in S.D. values $>0.67$ was considered significant catch-down growth in LGA subjects (25).

At 23-25 years of age, the following parameters were evaluated: height, weight, body mass index (BMI), abdominal circumference, and systolic and diastolic blood pressures. Serum samples were obtained and stored at $-20{ }^{\circ} \mathrm{C}$ until further analysis. Serum adiponectin was measured using Human Adiponectin RIA kit (Linco Research, Inc., St Charles, MO, USA). Intra- and interassay variations and sensitivity were $2.8,13.1 \%$, and $0.45 \mu \mathrm{g} / \mathrm{ml}$ respectively. In addition, plasma total cholesterol, high-density lipoprotein cholesterol (HDL-cholesterol), low-density lipoprotein cholesterol (LDL-cholesterol), triglycerides, insulin, glucose, and homeostasis assessment model (HOMA) IR were evaluated, as described elsewhere (26).

\section{Genotyping analyses}

Genomic DNA was isolated from peripheral blood leukocytes using QIAmp Blood Kit (Qiagen). Genotyping was performed by allelic discrimination in Real Time 7500 System (Applied Biosystems, Foster City, CA, USA) equipment. To analyze the SNP ADIPOQ $-11391 \mathrm{G}>\mathrm{A}$ (rs17300539), probes and primers were obtained from Applied Biosystems (assay ID C_33187774_10). PCR was performed in a total volume of $6.74 \mu \mathrm{l}$. The reaction consisted of $3.0 \mu \mathrm{l}$ genomic DNA (150 ng), $3.125 \mu$ TaqMan $2 \times$ Universal Master Mix (Applied Biosystems), $0.156 \mu \mathrm{l}$ primerprobe $(470 \mathrm{nM}$ and $100 \mu \mathrm{M}$ respectively) and $0.46 \mu \mathrm{l}$ DNAse/RNAse-free purified water. Previously known genotype DNA was used as a positive control and 
water was used as negative control. After initial $2 \mathrm{~min}$ at $50{ }^{\circ} \mathrm{C}, 10 \mathrm{~min}$ at $95^{\circ} \mathrm{C}$ followed by 40 cycles of $15 \mathrm{~s}$ at $92{ }^{\circ} \mathrm{C}$ and $60 \mathrm{~s}$ at $60^{\circ} \mathrm{C}$ were realized. The validity of RT-PCR results was verified by direct sequencing $5 \%$ of the samples using the BigDye FN Sequencing Kit (PE Applied Biosystems) and using the following primers: forward 5'-GCTCTGTGTGGACTGTGGAG-3'; reverse 5'-CTGCCACCCACTTAGGTGTT-3'. The agreement of the genotypes determined for the blinded quality control samples was $100 \%$.

\section{Statistical analysis}

Hardy-Weinberg equilibrium was tested by a goodnessof-fit $\chi^{2}$ test with one degree of freedom. Continuous variables were expressed as mean \pm s.D. The frequencies of genotypes and alleles were compared by $\chi^{2}$ test or Fisher's exact test. The odds ratio (OR) and their 95\% confidence interval $(\mathrm{CI})$ range were calculated for the recessive genetic model (variant allele homozygous versus the combined group of wild allele homozygous and heterozygous) and for the co-dominant genetic model. Differences in adiponectin levels and other cardiometabolic variables among genotypes and birth size groups were evaluated by two-way ANOVA. Since all continuous cardiometabolic variables analyzed, including adiponectinemia, could be influenced by body fat distribution, three models of adjustment were performed: adjustment for BMI and gender (model a); adjustment for abdominal circumference, height, and gender (model b); and adjustment for gender only (model c). For pairwise group comparisons, we used orthogonal contrasts, a technique for partitioning ANOVA sum of squares into individual degrees of freedom. The relationship between adiponectin levels and cardiometabolic variables was evaluated by Spearman's correlation test. A $P<0.05$ was considered statistically significant. Statistical analyses were performed using both SAS (Cary, NC, USA) and Graphpad Prism5 software (La Jolla, CA, USA).

\section{Results}

\section{Comparisons between AGA and LGA groups}

Body symmetry at birth was significantly different between LGA and AGA groups. There were more asymmetric newborns in LGA group. Frequencies of asymmetric heavy for length (PI>3.1) were 39 and $9.4 \%$ in LGA and AGA groups respectively $(P<0.0001)$.

The cardiometabolic characteristics of the subjects at 23-25 years are presented in Table 1. Subjects born LGA presented significantly higher adiposity than AGA subjects, as observed by higher BMI $(P=0.01)$ and abdominal circumference $(P=0.04)$. The prevalence of excessive weight $\left(\mathrm{BMI}>25 \mathrm{~kg} / \mathrm{m}^{2}\right)$ was significantly
Table 1 Cardiometabolic characteristics of the studied subjects at 23-25 years of age. Data are expressed in mean \pm S.D.

\begin{tabular}{lccc}
\hline & AGA & LGA & $\boldsymbol{P}$ \\
\hline$n(\mathrm{male} / \mathrm{female})$ & $392(178 / 214)$ & $116(60 / 56)$ & 0.24 \\
BMI $\left(\mathrm{kg} / \mathrm{m}^{2}\right)$ & $23.4 \pm 4.4$ & $25.7 \pm 4.9$ & $0.01^{\mathrm{c}}$ \\
Abdominal circumference & $80.2 \pm 11.9$ & $85.3 \pm 13.1$ & $0.04^{\mathrm{c}}$ \\
$\quad(\mathrm{cm})$ & & & \\
Systolic blood pressure & $116.4 \pm 14.7$ & $119.7 \pm 15.4$ & $0.04^{\mathrm{b}}$ \\
$\quad(\mathrm{mmHg})$ & & & \\
Diastolic blood pressure & $69.9 \pm 8.5$ & $72.4 \pm 10.6$ & $0.09^{\mathrm{a}}$ \\
$\quad(\mathrm{mmHg})$ & & & \\
Fasting glucose (mmol/l) & $4.6 \pm 0.5$ & $4.6 \pm 0.5$ & $0.5^{\mathrm{a}}$ \\
HOMA-IR & $1.3 \pm 1.1$ & $1.4 \pm 1.3$ & $0.01^{\mathrm{a}, \mathrm{b}}$ \\
Total cholesterol (mmol/l) & $4.23 \pm 0.9$ & $4.34 \pm 0.8$ & $0.9^{\mathrm{a}}$ \\
HDL cholesterol (mmol/l) & $1.3 \pm 0.3$ & $1.2 \pm 0.3$ & $0.3^{\mathrm{a}}$ \\
LDL cholesterol (mmol/l) & $2.5 \pm 0.8$ & $2.6 \pm 0.7$ & $0.6^{\mathrm{a}}$ \\
Triglycerides (mmol/l) & $0.97 \pm 0.5$ & $1.09 \pm 0.7$ & $0.8^{\mathrm{a}}$ \\
Adiponectin $(\mu \mathrm{g} / \mathrm{ml})$ & $11.3 \pm 6.6$ & $10.25 \pm 5.1$ & $0.39^{\mathrm{a}}$ \\
\hline
\end{tabular}

Two-way ANOVA for differences between birth sizes adjusted for a, BMI and gender; $b$, abdominal circumference, height and gender; $c$, gender. AGA, adequate for gestational age; LGA, large for gestational age.

higher in LGA than in AGA subjects (47.5 vs $27.4 \%$; $P=0.003)$. Systolic blood pressure and HOMA-IR were significantly higher in LGA than in AGA subjects ( $P=0.04$ and $P=0.01$ respectively). No significant differences in total cholesterol, HDL-cholesterol, LDLcholesterol, triglycerides, and fasting glucose were found. Mean adiponectin concentrations were $10.2 \pm 5.1$ and $11.3 \pm 6.6 \mu \mathrm{g} / \mathrm{ml}$ (not significant (NS)) for LGA and AGA subjects respectively. Serum adiponectin levels were gender dependent in both LGA and AGA groups, being higher in females than in males (LGA: 11.8 \pm 5.4 vs $9 \pm 5 \mu \mathrm{g} / \mathrm{ml} ; \quad P=0.006$ and AGA: $13.5 \pm 8.3$ vs $9.3 \pm 5.8 \mu \mathrm{g} / \mathrm{ml} ; P<0.0001)$. Adiponectin levels were positively correlated with HDL-cholesterol $(r=0.26$; $P<0.0001)$, and negatively correlated with BMI $(r=-0.25 ; P<0.0001)$, abdominal circumference $(r=-0.33 ; P<0.0001)$, fasting glucose $(r=-0.16$; $P=0.0003)$, IR $(r=-0.16 ; P=0.0004)$, triglycerides $(r=-0.12 ; P=0.005)$, systolic blood pressure $(r=-0.24$; $P<0.0001)$, and diastolic blood pressure $(r=-0.2$; $P<0.0001)$. There was no correlation between adiponectin levels at the age of 23-25 years and birth weight or gestational age.

Considering symmetry at birth, there were no significant differences in the cardiometabolic profile at the age of 23-25 years in LGA subjects. LGA subjects who went through catch-down of weight presented significant lower BMI and abdominal circumference than those who stood with overgrowth $(25 \pm 4$ vs $29.4 \pm 4 \mathrm{~kg} / \mathrm{m}^{2} ; P=0.0009$ and $84.7 \pm 13.2$ vs 93.9 $\pm 10.7 \mathrm{~cm} ; P=0.009)$. There was no significant difference in any other metabolic parameter, including adiponectinemia, between these two groups (data not shown). LGA subjects with catch-down of weight remained with increased adiposity (BMI: $25 \pm 4$ vs $23.4 \pm 4.4 \mathrm{~kg} / \mathrm{m}^{2}$; $P=0.03$ and abdominal circumference: $84.7 \pm 13.2$ vs 80.2 $\pm 11.9 ; P=0.03)$ than AGA. 
Association between SNP - 11391G $>A$, birth size, and cardiometabolic variables at the age of 23-25 years

Genotypic and allelic frequencies of the SNP $-11391 \mathrm{G}>\mathrm{A}$ are presented in Table 2. The $-11391 \mathrm{~A}$ variant allele was significantly associated with being born LGA $(P=0.04)$. The frequency of the rare genotype (AA) was significantly higher in LGA group than in AGA group $(P=0.03)$. This genotype was associated with a fourfold higher probability of being born LGA than AGA $(\mathrm{OR}=4.14$; 95\% CI: 1.16-16.7). This polymorphism was not associated with symmetry at birth or changes in postnatal growth pattern. The frequency of the A allele did not significantly differ between symmetric and asymmetric subjects in both LGA (0.15 vs 0.13 ; $P=0.65)$ and AGA (0.14 vs $0.15 ; P=0.92)$ groups. The same was observed in LGA subjects with or without catch-down of weight (0.18 vs $0.11 ; P=0.37)$.

The $-11391 \mathrm{~A}$ variant allele was associated with higher adiponectin levels at the age of 23-25 years, independently of birth size (GG: $10.7 \pm 6.2$ versus GA: $12.2 \pm 6.5$ versus AA: $14.2 \pm 6.8 \mu \mathrm{g} / \mathrm{ml} ; P<0.01$; Fig. 1). This association remained significant after adjustment by BMI and gender. Variant homozygous presented a tendency of higher HDL-cholesterol levels than wild-type homozygous and heterozygous (GG: $1.2 \pm 0.3$ versus GA: $1.2 \pm 0.3$ versus AA: $1.4 \pm 0.5$; $P=0.07)$. The genotype was not associated with variations in any other cardiometabolic variable analyzed in both groups (data not shown).

\section{Discussion}

In this study, we showed that in the beginning of adult life subjects born LGA present higher adiposity, higher systolic blood pressure, and higher HOMA-IR than those born AGA, suggesting that fetal overgrowth may

Table 2 Association between the single-nucleotide polymorphism $-11391 \mathrm{G}>\mathrm{A}$ of the $A D I P O Q$ gene and birth size.

\begin{tabular}{lccccc}
\hline \multicolumn{5}{c}{ Birth size } \\
\cline { 2 - 6 } & AGA & LGA & & \\
& $n(\%)$ & $n(\%)$ & $P$ & OR & $95 \% \mathrm{Cl}$ \\
\hline $\mathrm{G}$ & $712(90)$ & $200(86)$ & 0.04 & 1.6 & $1.01-2.47$ \\
$\mathrm{~A}$ & $72(10)$ & $32(14)$ & & & \\
$\mathrm{G} / \mathrm{G}$ & $324(83)$ & $89(76.7)$ & 0.03 & & \\
$\mathrm{G} / \mathrm{A}$ & $64(16)$ & $22(19)$ & & & \\
$\mathrm{A} / \mathrm{A}$ & $4(1)$ & $5(4.3)$ & & & \\
$\mathrm{G} / \mathrm{G}+\mathrm{G} / \mathrm{A}^{\mathrm{a}}$ & $388(99)$ & $111(95.7)$ & 0.032 & 4.14 & $1.16-16.7$ \\
$\mathrm{~A} / \mathrm{A}$ & $4(1)$ & $5(4.3)$ & & & \\
\hline $\mathrm{Alll}$ & & &
\end{tabular}

Allelic frequencies were compared by Fisher's exact test plus odds ratio (OR). Genotypes were compared by $\chi^{2}$ analysis. $\mathrm{Cl}$, confidence interval; $\mathrm{G}$, guanine: $A$, adenine. AGA, adequate for gestational age; LGA, large for gestational age. ${ }^{\mathrm{a}}$ Genetic recessive model.

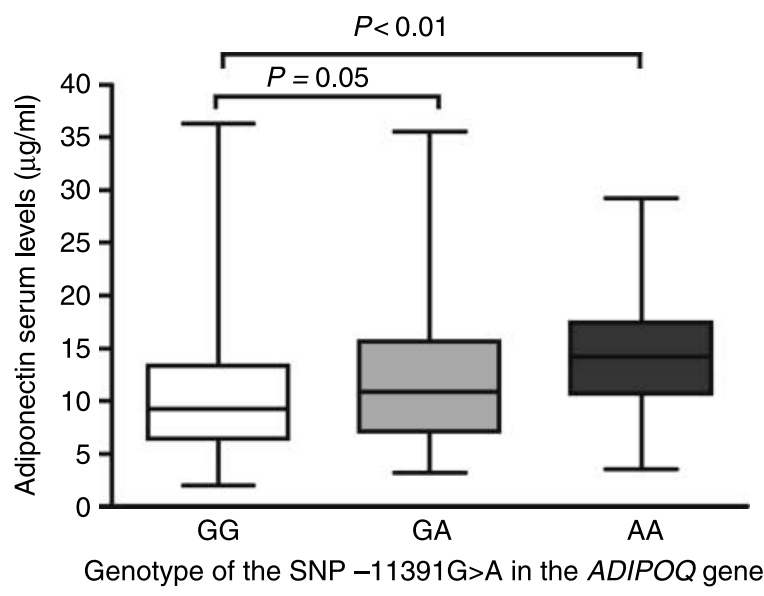

Figure 1 Adiponectin serum levels at 23-25 years of age according to $A D I P O Q-11391 \mathrm{G}>\mathrm{A}$ genotype. Data are expressed as mean \pm s.D. Difference between means assessed by two-way ANOVA adjusted for BMl and gender.

be associated with an unfavorable metabolic profile throughout life. We also demonstrated that adiponectin levels at the age of 23-25 years were not different between subjects born LGA or AGA; however, adiponectinemia was negatively correlated with adiposity, particularly with abdominal circumference and also with HOMA-IR. In addition, the ADIPOQ - 11391A variant allele was associated with an increased chance of being born LGA and also with higher adiponectin levels, regardless of birth size.

Body symmetry at birth is related to the underlying etiology of being born LGA. Asymmetric overgrowth is a common outcome of gestational diabetes, but it has been observed that LGA offspring of both diabetic and nondiabetic mothers presents abnormalities in insulin sensitivity $(5,27)$. It has been speculated that the body composition at birth influences cardiometabolic risk in LGA subjects $(28,29)$. However, our data do not confirm this hypothesis because symmetric and asymmetric LGA subjects did not differ in any anthropometric or metabolic trait in the beginning of adult life. Therefore, differences between symmetric and asymmetric LGA newborns in leptin, insulin, and glucose concentrations previously observed by others $(29,30)$ might not persist throughout life. Thus, body symmetry at birth may not predict metabolic outcome in adult life in LGA subjects.

We demonstrated that catch-down of weight during childhood is associated with a better cardiometabolic profile in LGA subjects at the age of 23-25 years. LGA subjects without catch-down of weight presented higher BMI and central adiposity than LGA subjects with catch-down of weight. Although the occurrence of catch-down of weight attenuates the unfavorable metabolic phenotype of LGA subjects, these subjects present higher adiposity than AGA controls. 
This finding is in agreement with a previous work in which children born LGA, even after experiencing catch-down growth, tended to persist with excessive weight throughout life (3).

To our knowledge, there is no data on anthropometric and metabolic outcome of LGA subjects when they reach adult life. Some previous data showed reduced insulin sensitivity in LGA newborns (27) and increased fat accumulation during childhood in LGA subjects $(2,31)$. In Pima Indians, fetal overgrowth was associated with higher systolic blood pressure at the age of 7-11 years (32). Our findings demonstrated that this unfavorable metabolic profile persists until adult life, as previously suggested in newborn and children born LGA $(2,27,31)$. Thus, one of the important findings in this study is that being born LGA has long lasting consequences, and these subjects are indeed at higher risk of developing metabolic syndrome later in life.

In the present study, adiponectin levels were not different between subjects born LGA or AGA. However, adiponectinemia was negatively correlated with adiposity, particularly with abdominal circumference and also with HOMA-IR, reinforcing the role of adiponectin as an insulin-sensitizing agent (12) and highlighting its influence in the development of metabolic syndrome. Studies have shown that adiponectin production is more related to central adiposity rather than to peripheral adiposity $(33,34)$. In addition, hypertropic adipocytes exert negative feedback on adiponectin expression (8). It has been shown that children born LGA presented augmented adiposity due to increased amount of adipose tissue and also larger adipocytes (35).

Growth-restricted neonates, including discordant twins, presented lower cord blood adiponectin levels (13, 15). Interestingly, cord blood adiponectin levels were also found to be lower in LGA newborns (36). There are two controversial studies on adiponectin levels in a relatively small number of prepubertal LGA children. One of them showed higher IR and lower adiponectin levels in Turkish nonobese prepubertal LGA than AGA children with similar BMI (37). However, a similar study in Greek prepubertal children found higher adiponectin levels in LGA subjects (38). To our knowledge, there is no data correlating adiponectin levels in adult life and birth size. In our study, a large number of LGA and AGA subjects have been followed from birth to young adult life, and no significant difference in adiponectinemia was observed between groups at the beginning of adult life. Altogether, these data suggest that in subjects born LGA, adiponectin can exert effects in prenatal life while in prepubertal and youth these effects are subtle; however, long-term follow-up is necessary to better assess whether variations in adiponectin levels can influence the development of metabolic syndrome in these subjects. These data are in accordance with evidence that adiponectin may be important in prenatal life. In human fetus, unlike in adults, adiponectin is also produced in extra-adipose tissues, including the placenta (14) where adiponectin receptors are also abundantly expressed (39).

Deletion of the region where the $-11391 \mathrm{G}>\mathrm{A}$ SNP is located increases the $A D I P O Q$ transcriptional activity, suggesting that the $G$ allele negatively modulates ADIPOQ transcription (40). Additionally, one in vitro transcriptional assay suggested that the rare $-11391 \mathrm{~A}$ allele may directly increase $A D I P O Q$ transcriptional activity (20). This result, however, was not recently reproduced (41), and these authors suggested linkage disequilibrium between this SNP and as yet unknown functional site in the promoter proximal region of ADIPOQ. Previous reports showed significant association of the $-11391 \mathrm{~A}$ allele with higher adiponectin levels in obese children and adults $(17,20,21)$. In Hispanic origin subjects, this variant allele was associated with lower visceral and visceral/subcutaneous adipose tissue ratio (42). Recently, this polymorphism has been associated with lower IR and protection of weight regain in obese subjects (43). Another variation $(-11377 \mathrm{C}>\mathrm{G})$ has been described in the vicinity of the $-11391 \mathrm{G}>\mathrm{A}$ polymorphism and they are in linkage disequilibrium. The $-11377 \mathrm{C}>\mathrm{G}$ polymorphism has been shown to be independently associated with circulating adiponectin levels, being its variant allele associated with lower adiponectinemia. These two polymorphisms define a 'low-level' haplotype associated with decreased adiponectin level, which explains more adiponectin variation than each of these two polymorphisms alone $(17,20)$. Further studies in our cohort might expand the understanding of the association of ADIPOQ variants and its modulation on adiponectinemia $(17,20)$.

No previous study has investigated the association between $A D I P O Q$ variants with birth size and adiponectinemia outcome later in life. In our study, the $-11391 \mathrm{~A}$ variant allele was associated with an increased chance of being born LGA. When comparing allele frequency, subjects carrying the polymorphic allele presented 1.6 times more chance of being born LGA. Regarding genotype distribution, subjects carrying the rare AA genotype presented a fourfold increased risk of being born LGA than the combined group of wild allele homozygous and heterozygous. It should be noted that the significant difference between the AA genotype (recessive model) only relies upon a very small number of subjects ( 4 vs 5 ). The co-dominant effect of the A allele on adiponectin levels is well known, as observed by us and previously by others (21). Concerning the co-dominant genetic model for birth size, the same effect was not observed in our series, possibly because of the relatively small number of heterozygous GA genotype in the LGA group. Thus, we cannot rule out that the effect of the $-11391 \mathrm{G}>\mathrm{A}$ polymorphism on birth size may be under a co-dominant genetic model. 
These data suggest that the $-11391 \mathrm{~A}$ allele may somehow facilitate fetal overgrowth. It might be due to enhanced growth-promoting effects of insulin by higher adiponectin levels. Additionally, higher adiponectin levels may increase insulin signaling in adipocytes, physiologically contributing to weight gain in both preand postnatal life (20).

Since the presence of the $-11391 \mathrm{~A}$ variant allele was shown to increase $A D I P O Q$ transcriptional activity $(20,44)$, we assessed the influence of different $-11391 \mathrm{G}>\mathrm{A}$ genotypes on adiponectin levels. In our cohort, we observed a gene dosage effect of the variant $\mathrm{A}$ allele on adiponectin levels. Wild-type homozygous presented lower adiponectin levels than heterozygous, and this difference was even more significant when compared with homozygous for the variant A allele. This result is in agreement with a co-dominant model for this variant allele. In this view, the association of the -11391 A allele with higher adiponectin levels in our pre-risk subjects may indicate its protective role in the development of cardiometabolic diseases. Indeed, in our cohort, we observed a tendency to higher HDLcholesterol levels in -11391 A carriers. On the other hand, LGA subjects presented increased cardiovascular risk, thus it seems to be a paradox the finding that the $-11391 \mathrm{~A}$ allele to be associated with an increased chance of being born LGA and also with higher adiponectin levels in early adult life. It is speculated that higher adiponectin-induced insulin sensitivity may increase lipid storage in adipose tissue but not in liver and muscle. Consequently, higher adiponectin protects from IR, and eventually from T2D, but on the other hand it could favor additional weight gain and predispose to obesity (20). It is unlikely that adiponectinemia alone would exert deleterious effects. Additionally, it is also possible that LGA status could be a concomitant event and not a trigger to cardiometabolic risk. Therefore, it would be interesting to follow up the $-11391 \mathrm{~A}$ carriers in order to verify the maintenance of their more favorable cardiometabolic outcome.

Some limitations of this study should be considered: lack of information on gestational diabetes history; however, the use of the PI may partially offset this deficiency; biochemical evaluations at birth, including serum adiponectin were not available. In our cohort, the variant $-11391 \mathrm{~A}$ allele was found in $10 \%$ of the subjects, which is similar to the distribution found in the European population (http://www.ncbi.nlm.nih.gov/projects/SNP/; Reference SNP Cluster report: rs17300539). Given the relative low frequency of this variant allele and considering the mixed ethnic background of the Brazilian population, our results need to be replicated in other different populations.

In summary, we showed that being born LGA has consequences in early adult life on cardiometabolic traits, even in pre-risk subjects. The $-11391 \mathrm{~A} A D I P O Q$ gene variant was associated with increased chance of being born LGA. In addition, independently of birth size, this allele was associated with higher adiponectin levels in early adult life. Therefore, the $-11391 \mathrm{~A}$ allele plays a role in prenatal growth and might exert a protective effect on cardiometabolic risk in later life.

\section{Declaration of interest}

There is no conflict of interest that could be perceived as prejudicing the impartiality of the research reported.

\section{Funding}

This work was supported by Fundaçao de Amparo a Pesquisa do Estado de Sao Paulo - FAPESP (grants: 07/58105-1 and 07/50713-2).

\section{Acknowledgements}

We are grateful to Mr José Roberto da Silva and Ms Adriana Rossi for their assistance with adiponectin measurement.

\section{References}

1 Dabelea D, Pettitt DJ, Hanson RL, Imperatore G, Bennett PH \& Knowler WC. Birth weight, type 2 diabetes, and insulin resistance in Pima Indian children and young adults. Diabetes Care 199922 944-950.

2 Boney CM, Verma A, Tucker R \& Vohr BR. Metabolic syndrome in childhood: association with birth weight, maternal obesity, and gestational diabetes mellitus. Pediatrics $2005115290-296$.

3 Hediger ML, Overpeck MD, Kuczmarski RJ, McGlynn A, Maurer KR \& Davis WW. Muscularity and fatness of infants and young children born small- or large-for-gestational-age. Pediatrics 1998 10260.

4 Dunger DB, Petry CJ \& Ong KK. Genetics of size at birth. Diabetes Care 200730 150-155.

5 Evangelidou EN, Kiortsis DN, Bairaktari ET, Giapros VI, Cholevas VK, Tzallas CS \& Andronikou SK. Lipid profile, glucose homeostasis, blood pressure, and obesity-anthropometric markers in macrosomic offspring of nondiabetic mothers. Diabetes Care 200629 1197-1201.

6 Pettitt DJ, Bennett PH, Saad MF, Charles MA, Nelson RG \& Knowler WC. Abnormal glucose tolerance during pregnancy in Pima Indian women: long-term effects on offspring. Diabetes 1991 40 126-130.

7 Persson B \& Hanson U. Fetal size at birth in relation to quality of blood glucose control in pregnancies complicated by pregestational diabetes mellitus. British Journal of Obstetrics and Gynaecology $1996103427-433$.

8 Yamauchi T, Kamon J, Waki H, Murakami K, Motojima K, Komeda K, Ide T, Kubota N, Terauchi Y, Tobe K, Miki H, Tsuchida A, Akanuma Y, Nagai R, Kimura S \& Kadowaki T. The mechanisms by which both heterozygous peroxisome proliferator-activated receptor gamma (PPARgamma) deficiency and PPARgamma agonist improve insulin resistance. Journal of Biological Chemistry 2001276 41245-41254.

9 Kim CS, Park JS, Park J, Nam JS, Kang ES, Ahn CW, Cha BS, Lim SK, Kim KR, Lee HC, Huh BK \& Kim DJ. Does birth weight predict adolescent adiponectin levels? Clinical Endocrinology 2006 $64162-168$.

10 Kadowaki T, Yamauchi NT, Kubota N, Hara K, Ueki K \& Tobe K. Adiponectin and adiponectin receptors in insulin resistance, diabetes, and the metabolic syndrome. Journal of Clinical Investigation $20061161748-1792$.

11 Heid IM, Wagner SA, Gohlke H, Iglseder B, Mueller JC, Cip P, Ladurner G, Reiter R, Stadlmayr A, Mackevics V, Illig T, 
Kronenberg F \& Paulweber B. Genetic architecture of the AMP1 gene and influence on adiponectin plasma levels and parameters of the metabolic syndrome in 1727 health Caucasians. Diabetes $200655375-384$.

12 Jazet IM, Pijl H \& Meinders AE. Adipose tissue as an endocrine organ: impact on insulin resistance. Netherlands Journal of Medicine 200361 194-212.

13 Mazaki-Tovi S, Kanety H, Pariente C, Hemi R, Yinon Y, Wiser A, Schiff E \& Sivan E. Adiponectin and leptin concentrations in dichorionic twins with discordant and concordant growth. Journal of Clinical Endocrinology and Metabolism 2009 $94892-898$.

14 Corbetta S, Bulfamante G, Cortelazzi D, Barresi V, Cetin I, Mantovani G, Bondioni S, Beck-Peccoz P \& Spada A. Adiponectin expression in human fetal tissues during mid- and late gestation. Journal of Clinical Endocrinology and Metabolism 200590 2397-2402.

15 Sivan E, Mazaki-Tovi S, Pariente C, Efraty Y, Schiff E, Hemi R \& Kanety H. Adiponectin in human cord blood: relation to fetal birth weight and gender. Journal of Clinical Endocrinology and Metabolism $2003 \mathbf{8 8} 5656-5060$.

16 Iñiguez G, Soto N, Avila A, Salazar T, Ong K, Dunger D \& Mericq V. Adiponectin levels in the first two years of life in a prospective cohort: relations with weight gain, leptin levels and insulin sensitivity. Journal of Clinical Endocrinology and Metabolism 2004 89 5500-5503.

17 Vasseur F, Helbecque N, Dina C, Lobbens S, Delannoy V, Gaget S, Boutin P, Vaxillaire M, Leprêtre F, Dupont S, Hara K, Clément K, Bihain B, Kadowaki T \& Froguel P. Single-nucleotide polymorphism haplotypes in the both proximal promoter and exon 3 of the APM1 gene modulate adipocyte-secreted adiponectin hormone levels and contribute to the genetic risk for type 2 diabetes in French Caucasians. Human Molecular Genetics 200211 2607-2014.

18 Hara K, Boutin P, Mori Y, Tobe K, Dina C, Yasuda K, Yamauchi T, Otabe S, Okada T, Eto K, Kadowaki H, Hagura R, Akanuma Y, Yazaki Y, Nagai R, Taniyama M, Matsubara K, Yoda M, Nakano Y, Kimura S, Tomita MJ, Kimura S, Ito C, Froguel P \& Kadowaki T. Genetic variation in the gene encoding adiponectin associated with and increased risk of type 2 diabetes in the Japanese population. Diabetes $200251536-540$.

19 Richardson DK, Schneider J, Fourcaudot MJ, Rodriguez LM, Arya R, Dyer TD, Almasy L, Blanfero J, Stern MP, DeFronzo RA, Duggirala R \& Jenkinson CP. Association between variants in the genes for adiponectin and its receptors with insulin resistance syndrome (IRS)-related phenotypes in Mexican Americans. Diabetologia $2006492317-2328$.

20 Bouatia-Naji N, Meyre D, Lobbens S, Séron K, Fumeron F, Balkau B, Heude B, Jouret B, Scherer PE, Dina C, Weill J \& Froguel P. ACDC/adiponectin polymorphisms are associated with severe childhood and adult obesity. Diabetes 200655 545-550.

21 Vasseur F, Helbecque N, Lobbens S, Vasseur-Dellanoy V, Dina C, Clément K, Boutin P, Kadowaki T, Scherer PE \& Froguel P. Hypoadiponectinaemia and high risk of type 2 diabetes are associated with adiponectin-encoding (ACDC) gene promoter variants in morbid obesity: evidence for a role of ACDC in diabesity. Diabetologia $2005 \mathbf{4 8} 829-899$.

22 Cardoso VC, Simões VM, Barbieri MA, Silva AA, Bettiol H, Alves MT \& Goldani MZ. Profile of three Brazilian birth cohort studies in Ribeirão Preto, SP and São Luís, MA. Brazilian Journal of Medical and Biological Research 200740 1165-1176.

23 Williams RL, Creasy RK, Cunnigham GC, Hawes WE, Norris FD \& Tashiro M. Fetal growth and perinatal viability in California. Obstetrics and Gynecology $198259624-632$.

24 Bonomo M, Corica D, Mion E, Gonçalves D, Motta G, Merati R, Ragusa A \& Morabito A. Evaluating the therapeutic approach in pregnancies complicated by borderline glucose intolerance: a randomized clinical trial. Diabetic Medicine 2005 22 1536-1541.
25 Ong KK, Ahmed ML, Emmett PM, Preece MA \& Dunger DB. Association between postnatal catch-up growth and obesity in childhood: prospective cohort study. BMJ 2000320 967-971.

26 Bustos P, da Silva AA, Amigo H, Bettiol H \& Barbieri MA. Metabolic syndrome in young adults from two socioeconomic Latin American settings. Nutrition, Metabolism, and Cardiovascular Diseases 200717 581-589.

27 Dyer JS, Rosenfeld CR, Rice J, Rice M \& Hardin DS. Insulin resistance in Hispanic large-for-gestational-age neonates at birth. Journal of Clinical Endocrinology and Metabolism 200792 3836-3843.

28 Schut AF, Janssen JA, Deinum J, Vergeer JM, Hofman A, Lamberts SW, Oostra BA, Pols HA, Witteman JC \& van Duijn CM. Polymorphism in the promoter region of the insulin-like growth factor I gene is related to carotid intima-media thickness and aortic pulse wave velocity in subjects with hypertension. Stroke $2003 \mathbf{3 4} 1623-1627$.

29 Van Assche FA. Symmetric and asymmetric fetal macrosomia in relation to long-term consequences. American Journal of Obstetrics and Gynecology 1997177 1563-1564.

30 Lepercq J, Lahlou N, Timsit J, Girard J \& Mouzon SH. Macrosomia revisited: ponderal index and leptin delineate subtypes of fetal overgrowth. American Journal of Obstetrics and Gynecology 1999 $181621-625$.

31 Beltrand J, Nicolescu R, Kaguelidou F, Verkauskiene R, Sibony O, Chevenne D, Claris O \& Lévy-Marchal C. Catch-up growth following fetal growth restriction promotes rapid restoration of fat mass but without metabolic consequences at one year of age. PLoS One 20094 5343-5351.

32 Bunt JC, Tataranni PA \& Salbe AD. Intrauterine exposure to diabetes is a determinant of hemoglobin A(1)c and systolic blood pressure in pima Indian children. Journal of Clinical Endocrinology and Metabolism 200590 3225-3229.

33 Yatagai T, Nagasaka S, Taniguchi A, Fukushima M, Nakamura T, Kuroe A, Nakai Y \& Ishibashi S. Hypoadiponectinemia is associated with visceral fat accumulation and insulin resistance in Japanese men with type 2 diabetes mellitus. Metabolism 2003 52 1274-1278.

34 Park KG, Park KS, Kim MJ, Kim HS, Suh YS, Ahn JD, Park KK, Chang YC \& Lee IK. Relationship between serum adiponectin and leptin concentrations and body fat distribution. Diabetes Research and Clinical Practice 200463 135-142.

35 Taşcă C, Chelaru E \& Sdrobici D. Fat cell size-body weight correlation in newborn. Endocrinology 197816 287-289.

36 Mazaki-Tovi S, Kanety H, Pariente C, Hemi R, Schiff E \& Sivan E. Cord blood adiponectin in large-for-gestational age newborns. American Journal of Obstetrics and Gynecology 2005193 $1238-1242$.

37 Darendeliler F, Poyrazoglu S, Sancakli O, Bas F, Gokcay G, Aki S \& Eskiyurt N. Adiponectin is an indicator of insulin resistance in non-obese prepubertal children born large for gestational age and is affected by birth weight. Clinical Endocrinology $2009 \mathbf{7 0}$ 710-716.

38 Giapros V, Evagelidou E, Challa A, Kiortsis D, Drougia A \& Andronikou S. Serum adiponectin and leptin levels and insulin resistance in children born large for gestational age are affected by the degree of overweight. Clinical Endocrinology 2007 66 353-359.

39 Caminos JE, Noguerias R, Gallego R, Bravo S, Tovar S, GarciaCaballero T, Casanueva FF \& Dieguez C. Expression and regulation of adiponectin and receptor in human and rat placenta. Journal of Clinical Endocrinology and Metabolism 2005 $904276-4286$.

40 Kita A, Yamasaki H, Kuwahara H, Moriuchi A, Fukushima K, Kobayashi M, Fukushima T, Takahashi R, Abiru N, Uotani S, Kawasaki E \& Eguchi K. Identification of the promoter region required for human adiponectin gene transcription: association with CCAAT/enhancer binding protein-beta and tumor necrosis factor-alpha. Biochemical and Biophysical Research Communications $2005331484-490$. 
41 Kyriakou T, Collins LJ, Spencer-Jones NJ, Malcolm C, Wang X, Snieder H, Swaminathan R, Burling KA, Hart DJ, Spector TD \& O'Dell SD. Adiponectin gene ADIPOQ SNP associations with serum adiponectin in two female populations and effects of SNPs on promoter activity. Journal of Human Genetics 200853 718-727.

42 Sutton BS, Weinert S, Langefeld CD, Williams AH, Campbell JK, Saad MF, Haffner SM, Norris JM \& Bowden DW. Genetic analysis of adiponectin and obesity in Hispanic families: the IRAS Family Study. Human Genetics 2005117 107-718.

43 Goyenechea E, Collins LJ, Parra D, Abete I, Crujeiras AB, O’Dell SD \& Martínez JA. The -11391 G/A polymorphism of the adiponectin gene promoter is associated with metabolic syndrome traits and the outcome of an energy-restricted diet in obese subjects. Hormone and Metabolic Research 2009 41 55-61.

44 Laumen H, Saningong AD, Heid IM, Hess J, Herder C, Claussnitzer M, Baumert J, Lamina C, Rathmann W, Sedlmeier EM, Klopp N, Thorand B, Wichmann HE, Illig T \& Hauner H. Functional characterization of promoter variants of the adiponectin gene complemented by epidemiological data. Diabetes 200958 984-891.

Received 28 September 2009

Accepted 14 October 2009 